\title{
A prospective study of social networks in relation to total mortality and cardiovascular disease in men in the USA
}

\author{
Ichiro Kawachi, Graham A Colditz, Alberto Ascherio, Eric B Rimm, \\ Edward Giovannucci, Meir J Stampfer, Walter C Willett
}

\begin{abstract}
Study objective - Previous studies have established a relationship between low levels of social networks and total mortality, but few have examined cause specific mortality or disease incidence. This study aimed to examine prospectively the relationships between social networks and total and cause specific mortality, as well as cardiovascular disease incidence.
\end{abstract}

Design - This was a four year follow up study in an ongoing cohort of men, for whom information on social networks was collected at baseline. The main outcome measures were total mortality, further categorised into deaths from cardiovascular disease (stroke and coronary heart disease), total cancer, accidents/suicides, and all other causes; as well as stroke and coronary heart disease incidence.

Participants - Altogether 32624 US male health professionals aged 42 to 77 years in 1988, who were free of coronary heart disease, stroke, and cancer at baseline.

Results - A total of 511 deaths occurred during 122911 person years of follow up. Compared with men with the highest level of social networks, socially isolated men (not married, fewer than six friends or relatives, no membership in church or community groups) were at increased risk for cardiovascular disease mortality (age adjusted relative risk, $1.90 ; 95 \%$ CI $1 \cdot 07$, 3.37) and deaths from accidents and suicides (age adjusted relative risk $2 \cdot 22$; $95 \%$ CI $0 \cdot 76,6 \cdot 47)$. No excess risks were found for other causes of death. Socially isolated men were also at increased risk of stroke incidence (relative risk, $2 \cdot 21$; $95 \% \mathrm{CI}, 1 \cdot 12,4 \cdot 35)$, but not incidence of non-fatal myocardial infarction.

Conclusions - Social networks were associated with lower total mortality by reducing deaths from cardiovascular disease and accidents/suicides. Strong social networks were associated with reduced incidence of stroke, though not of coronary heart disease. However, social networks may assist in prolonging the survival of men with established coronary heart disease.

\section{(f Epidemiol Community Health 1996;50:245-251)}

The association between social realtionships and health was originally described by Durk- heim, ${ }^{1}$ who reported an increased risk of suicide among socially isolated individuals. Subsequent epidemiological research has established that social networks predict not only the risk of suicide, but all-cause mortality. ${ }^{2}$ To date, eight prospective epidemiological studies have reported an increased risk of total mortality in socially isolated individuals. ${ }^{3-10}$ Despite the wealth of evidence on social networks and total mortality, some important questions remain unanswered.

Firstly, it is not clear whether the increased risk of total mortality reflects a generalised susceptibility to illnesses among socially isolated individuals, ${ }^{11}$ or whether such persons are at especially high risk of mortality from specific types of illness. There is some evidence that social isolation is associated with an increased risk of cardiovascular disease mortality ${ }^{612}$ and total cancer mortality. ${ }^{13}$ However, virtually all of the prospective studies to date have reported data on total, but not cause specific, mortality. Secondly, it is not known where along the spectrum of disease social networks exert their impact. The major prospective studies of social networks have examined mortality, but not disease incidence. Thus it is not clear whether social networks influence disease incidence, recovery, or case fatality. ${ }^{14}$

To address some of these unanswered questions about social networks, we prospectively studied the associations between social networks and subsequent disease incidence and cause specific mortality.

\section{Methods}

The health professionals follow-up study is a longitudinal study of risk factors for cardiovascular disease and cancer among 51529 US men aged 40 to 75 years in 1986 . The study population consists of 29683 dentists, 10098 veterinarians, 4185 pharmacists, 3745 optometrists, 2218 osteopathic physicians, and 1600 podiatrists. The study began in 1986 , when cohort members completed a mailed questionnaire on heart disease and cancer risk factors, medical history, and diet. Follow up questionnaires were sent in 1990 and 1992 to update this information.

ASSESSMENT OF SOCIAL NETWORKS AND OTHER EXPOSURES

All participants in the study were asked to complete the Berkman-Syme social networks 
index as part of the 1988 mailed questionnaire. The social networks index was originally developed in the Alameda County study, ${ }^{3}$ and is a composite measure of four types of social connection: marital status (married versus not married); sociability (frequency and number of contacts with extended family and close friends, rated on a scale of 1 to 5 , with high values associated with many contacts and low values with few); church group membership (yes versus no); and membership in other community organisations (yes versus none). Responses to the index are categorised into four levels of social connection: low networks (level I) - for example, characterised by individuals with low intimate contacts (not married, fewer than six friends or relatives), and no membership in either church or community groups; medium networks (level II); medium-high networks (level III); and high networks (level IV). Further details of the construction of the social networks index are described elsewhere. ${ }^{15}$

In addition to the assessment of social networks, we obtained information from the baseline and follow up questionnaires on the participants' medical history, current smoking habits, body mass index, levels of physical activity, alcohol intake, parental history of myocardial infarction (including the age of each parent at the first event), and participants' self reported history of diabetes mellitus, hypertension, and hypercholesterolaemia. The accuracy of a self reported diagnosis of hypertension was confirmed and reported in a validation study among 100 cohort members. ${ }^{16}$

\section{ASSESSMENT OF TOTAL AND CAUSE SPECIFIC MORTALITY}

The primary end points in our study comprised deaths from all causes that occurred between the return of the 1988 questionnaire and January 31, 1992. Most deaths were reported by next of kin, work associates, or postal authorities. In addition, the mortality surveillance included systematic searches of the vital records using the national death index to discover deaths among participants who were persistent non-responders to the questionnaire mailings. We estimate that more than $98 \%$ of the deaths are ascertained by these methods. ${ }^{17}$

Physicians reviewed death certificates and hospital or pathology reports to classify individual causes of death. As well as analysing total mortality, the deaths were grouped into four broad categories: cardiovascular diseases (coronary heart disease, ICD 9th revision codes 410 to 414 , and 798 ; and stroke ICD codes 430 to 438 ); total cancers (ICD 9th revision codes 140 to 209); external causes of injury (all ICD " $E$ " codes, which included deaths from accident, poisoning, suicide, and other trauma); and all remaining causes of death.

\section{ASSESSMENT OF CARDIOVASCULAR DISEASE} INCIDENCE

We also examined all incident cases of coronary heart disease and stroke occurring between the return of the 1988 questionnaire and January
31,1992 . We wrote to all participants reporting an incident myocardial infarction or stroke on the 1990 or 1992 questionnaires to request permission to review their medical records. A definite myocardial infarction was classified according to the criteria of the World Health Organization, ${ }^{18}$ and required symptoms plus either typical electrocardiographic changes or high levels of cardiac enzymes. A definite stroke was classified as confirmed if the criteria of the national survey of stroke were met. ${ }^{19}$ Incident cases of non-fatal myocardial infarction and non-fatal stroke were classified as "probable" if the hospital records could not be obtained but the event required admission to hospital and the diagnosis was corroborated by supplementary correspondence or telephone interview.

Fatal coronary heart disease was made up of cases of fatal myocadial infarction confirmed by hospital records or autopsy reports; cases of sudden cardiac death (defined below); plus other deaths from coronary heart disease as determined from death certificates, if evidence of previous coronary heart disease was available (either from hospital records or interviews with the next of kin) and this was the underlying and most plausible cause of death. In no instance did we use death certificate classification alone to categorise a death as due to coronary heart disease. Sudden cardiac death was defined as death occurring within 1 hour of the onset of symptoms in a man with no previous serious illness, for which no other plausible cause of death - other than coronary disease was reported.

Death due to stroke was ascertained by physician review of hospital records and autopsy reports. In this study, $92 \%$ of the non-fatal myocardial infarction and fatal coronary heart disease, and $87 \%$ of the non-fatal and fatal strokes were classified as definite events.

\section{STUDY POPULATION AND DATA ANALYSIS}

Because the onset of major illness could itself influence an individual's social networks, we excluded from analyses all members of the cohort who reported a diagnosis of myocardial infarction, stroke, or cancer (except nonmelanoma skin cancer) before the return of the 1988 questionnaire $(n=6115$ men $)$. We cannot exclude the possibility that some men had undiagnosed illnesses at baseline. On the other hand, there is no reason to believe that an undiagnosed illness would have affected an individual's social network. We additionally excluded 12790 men who after three mailings did not complete the main 1988 questionnaire but instead answered a shorter questionnaire that did not include the Berkman-Syme social networks index. This left a total of 32624 men available for follow up. After repeated mailings to non-respondents, including the use of certified mail, we obtained a $96 \%$ response rate to the 1990 questionnaire, and a $94 \%$ response rate to the 1992 questionnaire.

In the analyses, each participant accumulated person-months of follow up from the date of return of the 1988 questionnaire to 
Table 1 Age standardised distribution of risk factors in relation to level of social network index

\begin{tabular}{lllll}
\hline & \multicolumn{3}{l}{ Berkman-Syme social network index } \\
\cline { 2 - 5 } Risk factor & $I V$ (high) & $I I I$ & $I I$ & $I$ (low) \\
\hline No (\%) & $16807(51 \cdot 5)$ & $6216(19 \cdot 1)$ & $7706(23 \cdot 6)$ & $1895(5 \cdot 8)$ \\
Smoking (\%) & $7 \cdot 3$ & $9 \cdot 1$ & $9 \cdot 5$ & $12 \cdot 1$ \\
Hypertension (\%) & $19 \cdot 1$ & $20 \cdot 4$ & $20 \cdot 5$ & $2 \cdot 1$ \\
Diabetes (\%) & $2 \cdot 7$ & $2 \cdot 5$ & $2 \cdot 8$ & $16 \cdot 4$ \\
High cholesterol (\%) & $16 \cdot 8$ & $18 \cdot 0$ & $17 \cdot 4$ & $24 \cdot 9$ \\
Body mass index (kg/m ${ }^{2}$ ) & $25 \cdot 1$ & $25 \cdot 0$ & $24 \cdot 9$ & $12 \cdot 0$ \\
Parental history of MI before age 60 (\%) & $11 \cdot 7$ & $12 \cdot 5$ & $13 \cdot 1$ & $19 \cdot 6$ \\
Alcohol intake >15 g/d (\%) & $11 \cdot 4$ & $16 \cdot 0$ & $17 \cdot 0$ & $20 \cdot 1$ \\
Physical activity (MET-h/week) & $20 \cdot 0$ & $19 \cdot 5$ & $19 \cdot 5$ & $79 \cdot 3$ \\
Blood pressure check in in past 2 years (\%) & $86 \cdot 2$ & $83 \cdot 2$ & $82 \cdot 7$ & $62 \cdot 1$ \\
Cholesterol check in past 2 years (\%) & $70 \cdot 4$ & $65 \cdot 8$ & $57 \cdot 1$ \\
Screening physical exam in past 2 years (\%) & $66 \cdot 8$ & $64 \cdot 0$ & $60 \cdot 3$ & $57 \cdot 1$ \\
\hline
\end{tabular}

Table 2 Age adjusted and multivariate relative risks of total and cause specific mortality according to level of social network index 1988-92

\begin{tabular}{|c|c|c|c|c|c|}
\hline & \multicolumn{5}{|c|}{ Berkman-Syme social network index } \\
\hline & IV high & III & II & I (low) & Test for trend, $p$ \\
\hline \multicolumn{6}{|l|}{ Total mortality } \\
\hline Cases & 234 & 101 & 133 & 43 & \\
\hline Age adjusted $R R$ & $1 \cdot 00$ & $\begin{array}{c}1 \cdot 11 \\
(0 \cdot 88,1 \cdot 41)\end{array}$ & $\begin{array}{c}1.22 \\
(0.99,1.51)\end{array}$ & $\begin{array}{l}1 \cdot 57 \\
(1 \cdot 14,2 \cdot 17)\end{array}$ & 0.004 \\
\hline Multivariate $\mathrm{RR}^{*}$ & $1 \cdot 00$ & 1.06 & $1 \cdot 13$ & 1.38 & \\
\hline Cardiovascular disease & & $(0 \cdot 84,1 \cdot 35)$ & $(0.91,1.40)$ & $(0.99,1.93)$ & 0.06 \\
\hline \multicolumn{6}{|c|}{ Cardiovascular disease (stroke and coronary heart disease) } \\
\hline Age adjusted RR & $1 \cdot 00$ & $1 \cdot 28$ & 1.53 & 1.90 & \\
\hline Multivariate RR & $1 \cdot 00$ & $\begin{array}{c}(0.83,1 \cdot 96) \\
1 \cdot 21\end{array}$ & $\begin{array}{c}(1 \cdot 05,2 \cdot 24) \\
1 \cdot 44\end{array}$ & $\begin{array}{l}(1.07,3.37) \\
1.76\end{array}$ & $0 \cdot 006$ \\
\hline Total cancer & & $(0 \cdot 79,1 \cdot 87)$ & $(0 \cdot 98,2 \cdot 13)$ & $(0 \cdot 97,3 \cdot 16)$ & $0 \cdot 02$ \\
\hline Cases & 100 & 41 & 39 & 12 & \\
\hline Age adjusted $R R$ & $1 \cdot 00$ & 1.05 & 0.84 & $1 \cdot 02$ & \\
\hline Multivariate RR & $1 \cdot 00$ & 1.03 & $\begin{array}{l}(0.58 .1 .21) \\
0.78\end{array}$ & $\begin{array}{l}(0.56,1.84) \\
0.87\end{array}$ & 0.55 \\
\hline Accidents and suicides & & $(0 \cdot 71,1 \cdot 48)$ & $(0 \cdot 54,1 \cdot 13)$ & $(0 \cdot 47,1 \cdot 60)$ & $0 \cdot 25$ \\
\hline $\begin{array}{l}\text { Cases } \\
\text { Age adjusted RR }\end{array}$ & $\begin{array}{l}16 \\
1 \cdot 00\end{array}$ & $\begin{array}{l}10 \\
1 \cdot 68 \\
(0 \cdot 77,3 \cdot 66)\end{array}$ & $\begin{array}{l}18 \\
2 \cdot 48 \\
(1 \cdot 29,4 \cdot 75)\end{array}$ & $\begin{array}{l}4 \\
2 \cdot 22 \\
(0 \cdot 76,6 \cdot 47)\end{array}$ & \\
\hline Multivariate RR & $1 \cdot 00$ & $\begin{array}{c}1.62 \\
(0.73,3.59)\end{array}$ & $\begin{array}{c}2 \cdot 35 \\
(1 \cdot 19,4 \cdot 62)\end{array}$ & $\begin{array}{l}1.99 \\
(0.66,5.99)\end{array}$ & 0.02 \\
\hline $\begin{array}{l}\text { Other causes } \\
\text { Cases } \\
\text { Age adjusted RR }\end{array}$ & $\begin{array}{l}55 \\
1.00\end{array}$ & $\begin{array}{l}19 \\
0.88\end{array}$ & $\begin{array}{l}31 \\
1 \cdot 23\end{array}$ & $\begin{array}{l}13 \\
1.97\end{array}$ & \\
\hline Multivariate RR & $1 \cdot 00$ & $\begin{array}{c}(0.52,1 \cdot 48) \\
0.78 \\
(0.46,1.33)\end{array}$ & $\begin{array}{c}(0 \cdot 79,1 \cdot 89) \\
1 \cdot 09 \\
(0 \cdot 70,1 \cdot 70)\end{array}$ & $\begin{array}{c}(1 \cdot 09,3 \cdot 58) \\
1 \cdot 48 \\
(0 \cdot 79,2 \cdot 76)\end{array}$ & $\begin{array}{l}0.06 \\
0.32\end{array}$ \\
\hline
\end{tabular}

* Multivariate relative risks adjusted for age (5 year age categories), time period (1988-90; 1990-92), smoking status (never, former, and current in categories of 1 to 14,15 to 24 , and 25 or more cigarettes per day), history of hypertension, diabetes
mellitus, and hypercholesterolemia, diagnosis of angina pectoris, deciles of body mass index, parental history of myocardial mellitus, and hypercholesterolemia, diagnosis of angina pectoris, deciles of body mass index, parental history of myocardial
infarction before age 60 (yes/no), daily alcohol intake $(0,0 \cdot 41-4 \cdot 9,5 \cdot 0-14 \cdot 9,15 \cdot 0-24 \cdot 9,25 \cdot 0-49 \cdot 9$, or 50 or more g/day), and tertiles of physical activity.

January 31, 1992 (or, for those who died or developed cardiovascular disease, up to the date of the event). Proportional hazards models were used to adjust for age (in 5 year age categories), cigarette smoking (categorized as current smokers of 1 to 14,15 to 24 , or $25+$ cigarettes per day, past, or never smokers), alcohol intake $(0.0 \mathrm{~g} /$ day, $0.01-4.9,5.0-14.9$, $15 \cdot 0-24 \cdot 9,25 \cdot 0-49 \cdot 9$, and $50 \cdot 0$ or more $g /$ day), body mass index (deciles), history of hypertension, diabetes mellitus, hypercholesterolaemia, angina pectoris, family history of myocardial infarction before age 60, and physical activity (tertiles). When appropriate, we performed the Mantel test for linear trend across levels of social networks, and reported the two tailed $p$ values. ${ }^{20}$

\section{Results}

CHARACTERISTICS OF THE STUDY POPULATION Altogether $5 \cdot 8 \%$ of the study population were socially isolated (level I of the social networks index), while $23.6 \%$ were in level II (medium networks), $19 \cdot 1 \%$ were in level III (mediumhigh networks), and $51.5 \%$ were socially well integrated (level IV). We compared the age standardised distributions of health behaviours and risk factors across the levels of social networks (table 1). Socially isolated individuals were more likely to be current smokers and to drink more than $15 \mathrm{~g} /$ day alcohol ( $\mathrm{p}$ for linear trend across categories of social networks $<0.0001$, for both smoking and drinking). Socially isolated men were also less likely to have undergone a blood pressure check, a serum cholesterol check, or a physical examination during the past two years for screening purposes. Other health related habits were distributed similarly across the groups.

TOTAL MORTALITY

During the four years of follow up, 511 deaths occurred in 122911 person-years. One hundred and fifty three individuals died of cardiovascular diseases (135 coronary heart disease deaths and 18 stroke deaths); 192 of total 
Table 3 Age adjusted and multivariate relative risks of total, non-fatal, and fatal stroke incidence according to level of social network index 1988-92

\begin{tabular}{|c|c|c|c|c|c|}
\hline & \multicolumn{5}{|c|}{ Berkman-Syme social network index } \\
\hline & IV high & III & II & I (low) & Test for trend, $p$ \\
\hline \multicolumn{6}{|l|}{ Total stroke } \\
\hline Cases & & 21 & 33 & 10 & \\
\hline Age adjusted RR & $1 \cdot 00$ & 1.39 & $1 \cdot 82$ & $2 \cdot 21$ & \\
\hline Multivariate $\mathrm{RR}^{*}$ & 1.00 & $\begin{array}{l}(0 \cdot 82,2 \cdot 37) \\
1 \cdot 31\end{array}$ & $\begin{array}{l}(1 \cdot 15,2 \cdot 87) \\
1 \cdot 72\end{array}$ & $\begin{array}{l}(1 \cdot 12,4 \cdot 35) \\
2 \cdot 02\end{array}$ & 0.002 \\
\hline \multirow{2}{*}{\multicolumn{6}{|c|}{ Fatal stroke $\dagger$}} \\
\hline & & & & & \\
\hline Cases & 5 & 0 & 6 & 2 & \\
\hline Age adjusted RR & $1 \cdot 00$ & - & $\begin{array}{l}2 \cdot 64 \\
(0 \cdot 84,8 \cdot 27)\end{array}$ & $\begin{array}{l}3.64 \\
(0.78,16.9)\end{array}$ & 0.04 \\
\hline \multicolumn{6}{|l|}{ Non fatal stroke } \\
\hline Cases & 35 & 21 & 27 & 8 & \\
\hline Age adjusted $R R$ & $1 \cdot 00$ & $\begin{array}{l}1.55 \\
(0.90,2.66)\end{array}$ & $\begin{array}{l}1 \cdot 65 \\
(1 \cdot 00,2 \cdot 71)\end{array}$ & $\begin{array}{l}1.96 \\
(0 \cdot 92,4 \cdot 17)\end{array}$ & 0.02 \\
\hline Multivariate RR & $1 \cdot 00$ & $\begin{array}{l}1.50 \\
(0.87,2.60)\end{array}$ & $\begin{array}{l}1.61 \\
(0.97,2.67)\end{array}$ & $\begin{array}{l}1 \cdot 86 \\
(0.85,4 \cdot 06)\end{array}$ & $0 \cdot 03$ \\
\hline
\end{tabular}

* Multivariate relative risks adjusted for age (5 year age categories), time period (1988-90; 1990-92), smoking status (never, former, and current in categories of 1 to 14,15 to 24 , and 25 or more cigarettes per day), history of hypertension, diabetes mellitus, and hypercholesterolemia, diagnosis of angina pectoris, deciles of body mass index, parental history of myocardial infarction before age 60 (yes/no), daily alcohol intake $(0,0 \cdot 01-4 \cdot 9,5 \cdot 0-14 \cdot 9,15 \cdot 0-24 \cdot 9,25 \cdot 0-49 \cdot 9$, or 50 or more g/day), and tertiles of physical activity.

† Too few cases to perform multivariate analysis.

cancer; 48 of accidents and suicide; and 118 of other causes.

Compared with the group with the most social connections (level IV), socially isolated individuals (level I) were at 1.5 times the age adjusted risk of total mortality ( $p$ for trend across catégories of social networks index = 0.004) (table 2). Adjustment for a broad range of risk factors in multivariate analysis somewhat attenuated the association. The following components of the social networks index predicted total mortality (data not shown in tables): not being married (relative risk, $1 \cdot 41 ; 95 \% \mathrm{CI} 1 \cdot 07$, 1.87); not belonging to a church group (relative risk, $1.42 ; 95 \%$ CI $1 \cdot 19,1 \cdot 70)$; and the absence of close relatives (relative risk, $1.34 ; 95 \%$ CI $1 \cdot 01,1 \cdot 78)$.

\section{CAUSE SPECIFIC MORTALITY}

Socially isolated individuals were at increased risk of cardiovascular diseases ( $p$ for trend= 0.006 ), and accidents and suicides ( $\mathrm{p}$ for trend $=0.008$ ) though not total cancer ( $p$ for trend $=0.55$ ). Of the individual components of the social networks index, being unmarried was the strongest predictor of cardiovascular disease mortality (relative risk, $1.44 ; 95 \%$ CI $0 \cdot 88,2 \cdot 38$ ). We analysed stroke mortality separately from coronary heart disease mortality (data not shown in tables). Compared with the group with the highest level of social ties (level IV), the age adjusted relative risk of stroke mortality was $1.31(95 \%$ CI $0 \cdot 24,7 \cdot 23)$ among men in the medium-high group (level III), $4.90(95 \%$ CI $1.70,14.16)$ among men in the medium group (level II), and 6.59 (95\% CI $1 \cdot 78,24 \cdot 38$ ) among men in the low group (level I) ( $p$ for trend, 0.0008 , based on 18 deaths). By contrast, the association between social networks and coronary mortality was weaker: relative to the group with the highest level of social ties (level IV), the age adjusted relative risk of coronary heart disease mortality was $1.28(95 \%$ CI $0.82,1.99)$ among men in the medium-high group (level III), $1 \cdot 31$ ( $95 \%$ CI $0 \cdot 86,1.98$ ) among men in the medium group (level II), and 1.59 (95\% CI 0.84, 3.02) among men in the low group (level I) ( $\mathrm{p}$ for trend, 0.09 , based on 135 deaths).

Three components of the social networks index strongly predicted mortality from accidents and suicides: not being married (relative risk, $2.92 ; 95 \% \mathrm{CI} 1 \cdot 50,5 \cdot 67)$; not belonging to a church group (relative risk $1.99 ; 95 \%$ CI $1 \cdot 14,3.47)$; and the absence of close relatives (relative risk, 3.83; 95\% CI 1·97. 7·47). Twenty cases of suicide occurred during the four year study period. The age adjusted relative risk of suicide among individuals in the most socially isolated group (level I) was 3.22 (95\% CI 0.92 , $11 \cdot 22)$ compared with those in the most well connected group ( $\mathrm{p}$ for trend $=0 \cdot 12$ ). Previous studies have reported an association between social isolation and smoking related cancers. ${ }^{13}$ However, we found no significant association between social isolation and lung cancer mortality (relative risk in men with fewest social connections $=1.48 ; 95 \%$ CI $0 \cdot 43,5 \cdot 07 ; \mathrm{p}$ for trend $=0.52$, based on 39 cases).

\section{CORONARY HEART DISEASE AND STROKE INCIDENCE}

Altogether 104 incident cases of stroke (91 cases of non-fatal stroke, and 13 cases of fatal stroke) and 403 cases of incident coronary heart disease ( 275 cases of non-fatal myocardial infarction, and 128 cases of fatal coronary heart disease) occurred during the four year follow up. If a participant developed a new episode of stroke or heart attack and died within the two year interval between two successive follow up questionnaires, then this person was classified as having had an incident fatal event.

A strong dose-response gradient was found between the level of social networks and stroke incidence ( $p$ for trend, 0.008 ) (table 3 ). Increased risks were observed for both fatal and non-fatal stroke, although there were too few cases of fatal stroke to carry out multivariate analysis. In contrast to stroke, social isolation was not associated with the incidence of either total coronary heart disease or non-fatal myo- 
Table 4 Age adjusted and multivariate relative risks of total coronary heart disease, non-fatal myocardial infarction, and fatal coronary heart disease incidence according to level of social network, 1988-92

\begin{tabular}{|c|c|c|c|c|c|}
\hline & \multicolumn{5}{|c|}{ Berkman-Syme social network index } \\
\hline & IV high & III & $I I$ & $I$ (love) & Test for trend, $p$ \\
\hline \multicolumn{6}{|l|}{ Total comnary heart disease } \\
\hline Cases & 188 & 90 & 100 & 25 & \\
\hline Age adjusted $R R$ & 1.00 & $\begin{array}{l}1.27 \\
(0.99,1.63)\end{array}$ & $\begin{array}{c}1.16 \\
(0.91,1.47)\end{array}$ & $\begin{array}{l}1 \cdot 17 \\
(0.77,1 \cdot 77)\end{array}$ & $0 \cdot 17$ \\
\hline Multivariate $\mathrm{RR}^{*}$ & 1.00 & $\begin{array}{l}1.26 \\
(0.98,1.62)\end{array}$ & $\begin{array}{l}1 \cdot 13 \\
(0 \cdot 89,1 \cdot 45)\end{array}$ & $\begin{array}{l}1 \cdot 14 \\
(0 \cdot 74,1 \cdot 73)\end{array}$ & $0 \cdot 25$ \\
\hline \multicolumn{6}{|l|}{ Fatal cornnary heart disease } \\
\hline Cases & & 25 & 37 & 10 & \\
\hline Age adjusted RR & 1.00 & $\begin{array}{l}1.16 \\
(0.73,1.86)\end{array}$ & $\begin{array}{c}1.41 \\
(0.93,2 \cdot 14)\end{array}$ & $\begin{array}{l}1.52 \\
(0.78,2.98)\end{array}$ & 0.06 \\
\hline Multivariate $\mathrm{RR}^{*}$ & 1.00 & $\begin{array}{l}1 \cdot 10 \\
(0.68,1 \cdot 77)\end{array}$ & $\begin{array}{c}1 \cdot 34 \\
(0 \cdot 88,2 \cdot 04)\end{array}$ & $\begin{array}{l}1 \cdot 42 \\
(0 \cdot 72,2 \cdot 81)\end{array}$ & $0 \cdot 13$ \\
\hline \multirow{2}{*}{\multicolumn{6}{|c|}{$\begin{array}{l}\text { Non fatal myocardial infarction } \\
\text { Cases }\end{array}$}} \\
\hline & 132 & $\begin{array}{l}65 \\
1.32\end{array}$ & $\begin{array}{l}63 \\
1.05\end{array}$ & 15 & \\
\hline & & $(0.98,1.77)$ & $(0 \cdot 78,1 \cdot 41)$ & $(0.59,1.72)$ & 0.69 \\
\hline Multivariate RR* & $1 \cdot 00$ & $\begin{array}{l}1.32 \\
(0.98,1.79)\end{array}$ & $\begin{array}{c}1.04 \\
(0.76,1 \cdot 40)\end{array}$ & $\begin{array}{l}1.00 \\
(0.58,1.71)\end{array}$ & $0 \cdot 19$ \\
\hline
\end{tabular}

* Multivariate relative risks adjusted for age (5 year age categories), time period $(1988-90 ; 1990-92)$, smoking status (never, former, and current in categories of 1 to 14,15 to 24 , and 25 or more cigarettes per day), history of hypertension, diabetes mellitus, and hypercholesterolemia, diagnosis of angina pectoris, deciles of body mass index, parental history of myocardia infarction before age 60 (yes/no), daily alcohol intake $(0,0 \cdot 01-4 \cdot 9,5 \cdot 0-14 \cdot 9,15 \cdot 0-24 \cdot 9,25 \cdot 0-49 \cdot 9$, or 50 or more g/day), and tertiles of physical activity.

Table 5 Age adjusted and multivariate relative risks of sudden cardiac death and non-sudden cardiac death, according to level of social network index 1988-92

\begin{tabular}{|c|c|c|c|c|c|}
\hline & \multicolumn{5}{|c|}{ Berkman-Syme social network index } \\
\hline & IV high & III & $I I$ & $I$ (low) & Test for trend, $p$ \\
\hline \multicolumn{6}{|l|}{ Sudden cardiac death } \\
\hline Cases & 21 & 10 & 12 & 2 & \\
\hline Age adjusted RR & 1.00 & $\begin{array}{l}1 \cdot 24 \\
(0.58,2.63)\end{array}$ & $\begin{array}{l}1 \cdot 22 \\
(0 \cdot 60,2 \cdot 49)\end{array}$ & $\begin{array}{l}0.82 \\
(0.19,3.52)\end{array}$ & 0.78 \\
\hline Multivariate $\mathbf{R R}^{*}$ & $1 \cdot 00$ & $\begin{array}{l}1 \cdot 22 \\
(0 \cdot 57,2 \cdot 60)\end{array}$ & $\begin{array}{l}1 \cdot 10 \\
(0 \cdot 54,2 \cdot 26)\end{array}$ & $\begin{array}{l}0.68 \\
(0 \cdot 16,2.96)\end{array}$ & 0.94 \\
\hline Non-sudden cardiac death & & & & & \\
\hline $\begin{array}{l}\text { Cases } \\
\text { Age adjusted RR }\end{array}$ & $\begin{array}{l}35 \\
1.00\end{array}$ & $\begin{array}{l}15 \\
1.12\end{array}$ & 25 & 8 & \\
\hline Multivariate $\mathrm{RR}^{*}$ & 1.00 & $\begin{array}{l}(0.61,2.03) \\
1.05 \\
(0.57,1.94)\end{array}$ & $\begin{array}{c}(0.91,2.54) \\
1.48 \\
(0.88,2.49)\end{array}$ & $\begin{array}{l}(0 \cdot 91,4 \cdot 14) \\
1 \cdot 89 \\
(0 \cdot 87,4 \cdot 13)\end{array}$ & 0.05 \\
\hline
\end{tabular}

cardial infarction (table 4). There was a modest increase in risk of fatal coronary heart disease among individuals with the least social connections (multivariate relative risk, $1 \cdot 42 ; 95 \%$ CI $0.72,2 \cdot 81$ ). We examined this association in detail by separately analysing sudden cardiac death (45 cases) and non-sudden cardiac death (83 cases) (table 5). The rationale for performing this analysis was based on the theory that social relationships enhance disease survival through the provision of various types of support, for example, advice to stop smoking. ${ }^{21}$ If improved survival among individuals with already established disease is indeed the mechanism by which social relationships affect mortality, we would not expect to find a protective effect of social networks for sudden cardiac death, since by definition, death occurs within one hour of the onset of symptoms. Consistent with this hypothesis, we found no association between level of social ties and sudden cardiac death ( $p$ for trend, 0.94), but a dose-response gradient with risk of non-sudden cardiac death ( $p$ for linear trend $=0.05$ ) (table 5).

Finally, we assessed potential effect modification by smoking status and diagnosis of hypertension. Within strata of smoking status (never, former, and current smokers), the strongest association of social networks with total mortality was found among current smokers. The relative risk of total mortality in the least socially connected group was $2 \cdot 16$
(95\% CI $1 \cdot 10,4 \cdot 23)$ among smokers, $1 \cdot 73$ (95\% CI $1.09,2 \cdot 76)$ among former smokers, and $1.10(95 \% \mathrm{CI} 0.53,2.28)$ among never smokers. The smoking $\chi$ social isolation interaction term was statistically significant $(p<0.001)$. The impact of poor social networks on cardiovascular mortality was stronger in men with a diagnosis of hypertension (relative risk, $2.62 ; 95 \%$ CI $1.07,6.45$ ) than in men without hypertension (relative risk, $1.57 ; 95 \%$ CI $0.74,3.31$ ). When we ran a model assessing interaction, the hypertension $\chi$ social isolation term was statistically significant $(p=0 \cdot 01)$.

\section{Discussion}

Our findings are compatible with the notion that social networks reduce total-mortality by lowering deaths from cardiovascular disease and accidents/suicides. In previous studies, the relative risks of total mortality among the most socially isolated individuals ranged from $1 \cdot 8$ (in the Evans County study) to 4.0 (in the Gothenburg study), whereas the present study found a multivariate relative risk of about 1.4 . The smaller magnitude of risk found in the present study may be partly due to the high socioeconomic status and relative homogeneity of health professionals who continued our cohort. High socioeconomic status - associated with such resources as a high level of knowledge about health and disease, or access to health 
care and other material goods - may reduce some of the disadvantages of social isolation. ${ }^{2223}$ We were also able to adjust for a broader range of health behaviours and risk factors in this study compared with previous investigations. ${ }^{34}$ In terms of the magnitude of the association, an adjusted relative risk of total mortality of 1.4 is comparable to the effect of cigarette smoking on total mortality reported in some studies. $^{2425}$

Four potential pathways have been proposed through which social relationships might affect health.$^{14}$ Firstly they may have an affect through the provision of instrumental support, such as financial assistance or services in kind. Such tangible assistance could contribute to the recovery and survival of patients after major illness (such as stroke), independent of professional medical services. A second pathway is through the provision of information and advice that might assist individuals to seek medical care services, or to adopt more health promoting behaviours, such as smoking cessation. The existence of such a pathway is supported by two of our findings: that socially isolated men were less likely to undergo medical screening (table 1) and, secondly, that the effects of poor social networks were strongest among those who smoked or had hypertension. If risky health behaviours (such as smoking) are in the pathway through which poor social networks act, then control for such behaviours in multivariate analyses may constitute statistical over adjusment and attenuate the reported associations towards the null.

A third postulated pathway linking social networks to health is the provision of emotional support. A recent report ${ }^{26}$ indicated that after an acute myocardial infarction, patients who lacked emotional support were nearly three times as likely to die during the first 6 months (odds ratio, $2 \cdot 9 ; 95 \%$ CI $1.2,6 \cdot 9$ ) compared with patients who received emotional support. A limitation of our study is that we did not collect data on such functional aspects of social ties. Thus, we are unable to distinguish the relative importance of different types of social support (eg, emotional, instrumental, informational) for the maintenance of health.

It has been suggested that social networks may directly influence host resistance and susceptibility to disease through alterations in neuroendocrine and immunological control systems. ${ }^{112728}$ For example, stress induces a sustained increase in cortisol and insulin levels, which in turn may lead to hyperlipidaemia and accelerate atherogenesis. ${ }^{29}$ However, few studies have actually demonstrated altered neuroendocrine control under conditions of stress. ${ }^{30}$ Importantly, our data failed to corroborate the hypothesis of generalised disease susceptibility. Increased risks were found only for suicide (confirming Durkheim's original observation), and cardiovascular disease mortality.

Our analyses of coronary heart disease incidence suggest that social relationships affect survival following the onset of coronary heart disease, but not the incidence of new disease. A prospective study of social networks among
Japanese-Americans residing in Hawaii ${ }^{31}$ also found no association with incidence of nonfatal myocardial infarction. In our data, poor social ties were associated with an increased risk of fatal coronary heart disease, but only if sudden cardiac deaths were excluded as an end point. The finding that social networks have little or no influence on the risk of sudden cardiac death suggests that the protective mechanisms associated with social ties operate after the onset of illness. This interpretation is also consistent with several prospective studies among patients with established coronary heart disease, ${ }^{2632-35}$ in which social relationships were found to predict survival after acute myocardial infarction.

The association of strong social ties with reduced stroke mortality was previously described in the Alameda County study. ${ }^{3}$ To our knowledge, no other study has reported a protective effect of social networks on stroke incidence. Several previous studies have reported a protective effect of social ties on cancer survival, ${ }^{133536}$ although the evidence has been inconsistent ${ }^{3738}$ depending on the stage of the cancer and the tumour site. We found no association of total cancer mortality with social ties, although our four year follow up period cannot exclude an effect on long term survival. We caution that some of our disease specific findings are based on limited duration of follow up with small numbers of cases. Nonetheless, our data suggest that social networks may improve the outcome of established disease, especially cardiovascular disease.

This study was supported by research grants HL 35464 and CA 55705 from the National Institutes of Health. We thank the participants of the health professionals follow up study for their continued cooperation and participation; and Mr Mark their continued cooperation and participation; and Mr Mark Shneyder, Ms Betsy Frost-Hawes, Ms Mitzi Wolff, Ms Kerry
Pillsworth, Ms Karen Corsano, Mr Steve Stuart, and Ms Mira Koyfman for help with compiling the data and preparing the paper.

1 Durkheim E. Suicide. New York: Free Press, 1951

2 House JS, Landis KR, Umberson D. Social relationships and health. Science 1988;214:540-45.

3 Berkman LF, Syme SL. Social networks, host resistance and mortality: a nine-year follow-up study of Alamed County residents. Am f Epidemiol 1979;109:186-204.

4 House JS, Robbins C, Metzner HL. The association of social relationships and activities with mortality: prospective evidence from the Tecumseh Community health study. Am ₹ Epidemiol 1982;116:123-40.

5 Schoenbach VJ, Kaplan BH, Fredman L, et al. Social ties and mortality in Evans County, Georgia. Am $\mathcal{F}$ Epidemiol 1986;123:577-91.

6 Kaplan GA, Salonen JT, Cohen RD, Brand RJ, Syme SL Puska P. Social connections and mortality from all causes and from cardiovascular disease: prospective evidence from Eastern Finland. Am f Epidemiol 1988;128:370-80

7 Orth-Gomer K, Johnson J. Social network interaction and mortality. A six-year follow-up study of a random sample of the Swedish population. $f$ Chronic Dis 1987;40:949-58. 8 Welin L, Tibblin G, Svardsudd K, et al. Prospective study of social influences on mortality. Lancet 1985;i:915-18.

9 Blazer DG. Social support and mortality in an elderly community population. Am f Epidemiol 1982;115:684-94.

10 Seeman TE, Berkman LF, Kohout F, LaCroix A, Glynn R, Blazer D. Inter-community variations in the association between social ties and mortality in the elderly: A comdemiology 1993;3:325-35.

11. Cassel J. The contribution of the social environment to host resistance. Am F Epidemiol 1976;104:107-23.

12 Berkman L, Breslow L. Health and ways of living: findings from the Aladema County study. New York: Oxford University Press, 1983.

13 Reynolds P, Kaplan GA. Social connections and risk for cancer: Prospective evidence from the Alameda County study. Behav Med 1990;16:101-10.

14 Berkman LF. The relationship of social networks and socia support to morbidity and mortality. In: Cohen S, Syme SL eds. Social support and health. New York: Academic Press, 1985;241-62. 
15 Berkman LF. Social networks, host resistance, and mortality: A follow-up study of Alameda County residents. University of California, Berkeley, 1977. PhD thesis.

16 Ascherio A, Rimm EB, Giovannucci EL, et al. A prospective study of nutritional factors and hypertension among US study of nutritional factors and hyp
men. Circulation 1992;86:1474-84.

17 Stampfer MJ, Willett WC, Speizer FE, et al. Test of the National Death Index. Am $\mathcal{f}$ Epidemiol 1984;119:837-9.

18 Rose GA, Blackburn H. Cardiovascular survey methods. 2nd ed. Geneva, Switzerland: World Health Organization, 1982

19 Walker AE, Robins M, Weinfeld FD. The National survey of stroke: clinical findings. Stroke 1981;12(suppl I):113-44

20 Rothman KJ, Boice JD Jr. Epidemiologic analysis with a programmable calculator. NIH publication no 79-1649. Washington, DC: Public Health Service, 1979

21 House JS, Kahn RL. Measures and concepts of social support. In: Cohen S, Syme SL eds. Social support and health. New York: Academic Press, 1985;83-108.

22 Kaplan GA, Keil JE. Socioeconomic factors and cardiovascular disease: a review of the literature. Circulation vascular disease:

23 Syme SL, Berkman LF. Social class, susceptibility and sickness. Am f Epidemiol 1976;104:1-8.

24 Doll R, Hill AB. Lung cancer and other causes of death in relation to smoking. A second report on the mortality of British doctors. $B M \mathcal{F}$ 1956;ii:1071-81.

25 Hammond EC. Smoking in relation to the death rates of one million men and women. In: Haenszel $W$ ed. Epidemiological approaches to the study of cancer and other chronic diseases, National Cancer Institute Monograph 19. Bethesda MD: US Department of Health, Education and Welfare, Public Health Service, National Cancer Institute; 1966:127-204.

26 Berkman LF, Leo-Summers L, Horwitz RI. Emotional support and survival after myocardial infarction. A proport and survival after myocardial infarction. A pro-
spective, population-based study of the elderly. Ann Intern Med 1992;117:1003-9.
27 Antonovsky A. Breakdown: a needed fourth step in the conceptual armamentarium of modern medicine. $\mathrm{Soc} S \mathrm{C}$ Med 1972;6:537-44.

$28 \mathrm{Cobb}$ S. Social support as a moderator of life stress. $\mathcal{f}$ Psychosom Med 1976;38:300-14.

29 Brindley D, Rolland Y. Possible connections between stress, diabetes, obesity, hypertension and altered lipoprotein metabolism that may result in atherosclerosis. Clin Sci 1989;77:435-61.

30 McEwan BS, Stellar E. Stress and the individual. Mechanisms leading to disease. Arch Intern Med 1993;153 2093-101.

31 Reed D, McGee D, Yano K, Feinleib M. Social networks and coronary heart disease among Japanese men in Hawaii. Am f Epidemiol 1983;117:384-96.

32 Ruberman W, Weinblatt E, Goldberg JD, Chauhary BS Psychosocial influences on mortality after myocardial infarction. N Engl f Med 1984;13:641-54.

33 Case RB, Moss AJ, Case N, McDermott M, Eberly S. Living alone after myocardial infarction. Impact on prognosis. alone after myocardial in

34 Williams RB, Barefoot JC, Califf RM, et al. Prognostic importance of social and economic resources among medically treated patients with angiographically documented coronary artery disease. $\mathcal{F} A M A$ 1992;267:520-4.

35 Vogt TM, Mullooly JP, Ernst D, Pope CR, Hollis JF. Socia networks as predictors of ischemic heart disease, cancer, stroke and hypertension: incidence, survival and mortality. f Clin Epidemiol 1992;45:659-66.

36 Goodwin JS, Hunt WC, Key CR, Samet JM. The effect of marital status on stage, treatment, and survival of cancer patients. $7 A M A$ 1987;258:3125-130.

37 Cassileth BR, Lusk EJ, Strouse TB, Miller DS, Brown LL, Cross PA, Tenaglin AN. Psychosocial status in chronic illness. N Engl f Med 1984;311:506-11.

38 Ell K, Nishimoto R, Mediansky L, Mantell J, Hamovitch M. Social relationships, social support and survival among patients with cancer. F Psychosom Res 1992;36:531-41. 